\title{
IDEOLOGIA E SUJEITO NO DISCURSO DA CONTABILIDADE
}

\section{ARTIGO ORIGINAL}

BOMBARDELLI, Joel ${ }^{1}$

BOMBARDELLI, Joel. Ideologia e sujeito no discurso da contabilidade. Revista Científica Multidisciplinar Núcleo do Conhecimento. Ano 05, Ed. 05, Vol. 03, pp. 56 65. Maio de 2020. ISSN: 2448-0959, Link de acesso: https://www.nucleodoconhecimento.com.br/contabilidade/ideologia-e-sujeito

\section{RESUMO}

Nesse trabalho, discutiremos a contabilidade como um discurso em movimento, privilegiando o efeito de sentidos, o sujeito e a ideologia. Articulando a contabilidade e as relações sociais, buscamos compreender a discursividade da contabilidade, conforme Michel Pêcheux ensina, sobre o objeto da linguística (o próprio da língua), o discurso. Por meio da análise discursiva interrogamos o sentido estabilizado da contabilidade e deslocamos para um espaço que trabalha o sentido e suas tensões, os sentidos escapando da norma, percorrendo o cotidiano social, interrogando o semanticamente normal, um lugar de equívoco. Nossas análises indicam o discurso contábil, que tenta produzir uma aparente neutralidade e exclusão política e ideológica, mas, contudo, funcionam pelo assujeitamento de sentidos e sujeitos. Compreendemos a contabilidade como um lugar de umta prática discursiva que dissimula o funcionamento político dos sentidos e, consequentemente, a própria ideologia.

Palavras-Chave: Análise de Discurso, contabilidade, sujeito, ideologia.

1 Doutorado em Ciências da Linguagem (UNIVÁS), Mestre em Engenharia da Produção (UFSC), Graduado em Ciências Contábeis (UNIR). 


\section{INTRODUÇÃO}

Nosso objetivo, neste trabalho, é apresentar o discurso contábil como produção de sentidos e sujeitos, ou seja, o modo como os sujeitos, os sentidos, a ideologia e a contabilidade estão ligados. O modo como funciona um discurso aparentemente estabilizado no espaço social, constituindo os sujeitos em suas relações, em suma, de significá-los. Compreendemos a prática contábil como decisiva para a forma com que sujeitos se (re)significam com a sua própria condição de existência, significando para si e para os outros, dessa maneira, como a sociedade significa os sujeitos em seus espaços, lugares econômicos-sociais.

Para compreender este processo de significação que articula contabilidade, sujeito e sociedade, colocamos as ciências contábeis como práticas ideológicas de (re)produção contínua dos modos de produção, funcionando como um discurso dominante, uma linguagem dos negócios, do patrimônio, do capital e do poder.

A linguagem dos negócios é uma das linguagens mais vibrantes do capitalismo e articula-se por memórias organizadas. Consideramos uma discursividade que promove sentidos de liberdade, iniciativa individual, transparência, concorrência etc., como racionalidades que regulam as relações sociais dos sujeitos em redes de significantes. A contabilidade pode funcionar como uma máquina de produção homogeneizante de sentidos, possivelmente, pelos seus textos e documentos normatizados. Contudo a interpretação e a análise que trilham os caminhos da Análise de Discurso são outras.

Nossos estudos e pesquisas, sobre Análise do Discurso e contabilidade, propõem observar o discurso contábil pela maneira de como se dão os modos de subjetivação em conflito entre o que o individualiza e o que relaciona um sujeito a outro no espaço capitalista, patrimonial. Vamos expor resultados de nossas análises sobre esta relação entre a ideologia, sujeito e a contabilidade. 


\section{DISCURSO, SUJEITO E IDEOLOGIA}

As questões relacionadas à língua/linguagem, não são somente objetos de estudos dos linguistas. Há variadas maneiras de entender a linguagem, pois é aprofundando nas diversidades de estudos da linguagem que filiamos os estudos das ciências contábeis, o discurso contábil aos ensinamentos de Michel Pêcheux na sua proposta particular de Análise do Discurso.

A Análise do Discurso não trata da língua, não trata da gramática. Ela trata do discurso. Trata "de curso, de percurso, de ocorrer por, de movimento. O discurso é assim palavra em movimento, prática de linguagem: com o estudo do discurso observa-se o homem falando" (ORLANDI, 2015, p.7). Pêcheux propõe uma compreensão do discurso como processos discursivos e remetido a relações de sentido que o produziram, isto é, um discurso sempre remete a outro discurso anterior. O processo discursivo é assim definido por Pêcheux:

[...] o processo discursivo não tem, de direito, início: o discurso se conjuga sempre sobre um discurso prévio, ao qual se atribui o papel de matéria prima, e o orador sabe que quando evoca tal acontecimento, que já foi objeto do discurso, ressuscita no espírito dos ouvintes o discurso no qual este acontecimento era alegado, com as 'deformações' que a situação presente introduz e da qual pode tirar partido (PÊCHEUX, 1997 [1969], p. 77, grifo autor).

O discurso é o homem falando produzindo sentido. O sentido tratado como "relação a", "relação com", conforme definição de Canguilhem (2006). "Falar é significar, dar a entender, porque pensar é viver no sentido. O sentido não é relação entre..., ele é em relação com.... Eis porque ele escapa a qualquer redução que tente inseri-lo numa configuração orgânica mecânica" (CANGUILHEM, 2006, p.203). O homem pode brincar com o sentido, usar as palavras produzindo desvios, simulando, produzir engodo, enganar (se), o discurso produz sentidos com relação "a", com relação "com", o indivíduo interpelado em sujeito pelo funcionamento da ideologia. 
A nossa identidade de que "eu" sou "eu" e "você" é "você", compreendemos como o resultado de uma interpelação histórica do sujeito jurídico, capitalista, ou seja, "o sujeito se constitui por uma interpelação - que se dá ideologicamente pela sua inscrição em uma formação discursiva[...] Esta forma-sujeito corresponde, historicamente, ao sujeito do capitalismo" (ORLANDI, 2015, p. 43). O funcionamento da ideologia se dá pela produção de evidências, "colocando o homem na relação imaginária com suas condições reais de existência" (ORLANDI, 2015, p. 44), fazendo parecer que não existam outros modos de dizer algo, naturalizando sentidos e as condições de existência.

Pêcheux e Fuchs (1997, [1975]), compreendem o materialismo histórico de Marx para a teoria do discurso, no funcionamento ideológico, na interpelação, no assujeitamento do sujeito como sujeito ideológico da superestrutura ideológica, ligada ao modo de produção dominante de uma certa formação social.

Em outras palavras, a região da ideologia deve ser caracterizada por uma materialidade específica articulada sobre a materialidade econômica: mais particularmente o funcionamento da instância ideológica deve ser concebido como "determinado em última instância" pela instância econômica, na medida em que aparece como uma das condições (não-econômicas) da reprodução da base econômica, mais especificamente das relações de produção inerentes a esta base econômica. (PÊCHEUX e FUCHS, 1997, [1975], p. 165)

Os aparelhos ideológicos de Estado asseguram as condições da reprodução contínua das relações econômicas e não-econômicas, colocando em jogo práticas de alianças e dominações, sem decalcar o espaço social, como se fosse vontade dos sujeitos, livres para escolher e ocupar o seu lugar no espaço econômico-social. Dessas condições de (re)produção, resultam as formações discursivas pelo funcionamento da ideologia. O sujeito ocupa lugares e produz discursos sob a ilusão de ser a fonte, origem do seu discurso. Sobre o funcionamento da ideologia, ou seja, a ideologia interpelando os indivíduos como sujeitos, Althusser afirma: 
[...] a categoria de sujeito é constitutiva de toda a ideologia, mas ao mesmo tempo e imediatamente acrescentamos que a categoria de sujeito só é constitutiva de toda ideologia, na medida em que toda a ideologia tem por função (que a define) 'constituir' os indivíduos concretos em sujeitos. É neste jogo de dupla constituição que consiste o funcionamento de toda ideologia, pois que a ideologia não é mais que o seu próprio funcionamento nas formas materiais da existência deste funcionamento. (ALTHUSSER, 1970, p. 94)

Nessa perspectiva, compreendemos o sujeito no discurso contábil, que interpelado pela ideologia, ocupa lugares, formas materiais de existência, por sua formação discursiva, com a ilusão de sempre saber o que fala, de ser fonte de sentido, como se fosse transparente. Contudo, a contabilidade não é somente prática técnica, funciona também como prática política, ideológica, teórica e social.

\section{A CONTABILIDADE E A ANÁLISE DO DISCURSO}

As ciências contábeis, a partir das suas formulações assertivas "técnicas/cientificas", produzem efeitos de sentidos que ultrapassam a questão estabilizada da terminologia e da linguagem contábil. Na concepção de Orlandi (2004, p. 23), a ciência se constitui em pressupostos de certas noções de linguagem e de sujeito. Assim, a contabilidade se funda também sobre tais noções. O sujeito aqui, o contador, se constitui sujeito à língua, à história e à ideologia.

A contabilidade se apoia numa teoria de linguagem com terminologia específica, o que Ihe permite ser concebida enquanto uma linguagem (HENDRIKSEN; BREDA, 1999, p. 29), uma linguagem dos negócios, dos números, dos valores, da mensuração. $A$ contabilidade se formula ao modo de uma metalinguagem, como se assim o fosse. Pois, produz, como efeito, a aparência de sua suposta neutralidade enquanto formulação - como se não fosse marcada pela ideologia, que, como sabemos pela Análise de Discurso de Pêcheux, a ideologia interpela os sujeitos, inclusive os da ciência, os técnicos. 
O próprio significado da contabilidade ou das ciências contábeis é pleno de incompletude, produz sempre uma outra possibilidade de interpretação, desliza, deriva para o funcionamento da metáfora. A palavra "conta", por sua polissemia, pode produzir diferentes efeitos de sentidos. Essa polissemia depende do contexto histórico e dos efeitos de sentidos de "quem fala", para "quem fala" e "onde fala", ou seja, na elaboração das paráfrases, torna-se possível observar a possibilidade de produção de diferentes sentidos. As ciências contábeis, por sua teoria e prática técnica, têm qualidades políticas, portanto ideológicas e estão no mesmo processo, em continuidade nas relações sociais, como define Thomas Herbert (pseudônimo utilizado por Michel Pêcheux nos seus primeiros trabalhos nos meados dos anos de 1960):

Os conteúdos ideológicos existem, dissemos, em continuidade com as práticas técnicas e política: o segredo que cerca a ideologia e que nos propomos a examinar tem, então, alguma coisa a ver com as próprias, em seu desenvolvimento próprio e em suas relações recíprocas. (HERBERT, 2016, p. 28)

No jogo de metalinguagem e terminologia, como um espaço estabilizado, entre a língua e o saber linguístico, há sempre espaço de interpretação. A linguagem não é transparente, funciona para a produção de sentidos, e os sentidos são construídos a partir do sujeito histórico e ideológico (ORLANDI, 2015; PÊCHEUX, 1990). A linguagem contábil se filia as estas concepções, pois os usuários da informação contábil (gestores, investidores, bancos, governos etc.) a interpretam demonstrando certa filiação a determinada(s) rede(s) de sentidos, que funcionam por cada formação ideológica ou lugar que ocupa $(\mathrm{m})$. Segundo Haroche et al., (HAROCHE et al., 1971, apud PÊCHEUX e FUCHS, 1997 [1975], p. 166): "cada formação ideológica constitui um conjunto complexo de atividades e representação que não são nem individuais nem universais, mas se reportam mais ou menos diretamente, às posições de classe em conflito umas das outras".

A contabilidade, como provedora da informação dos negócios, instaura em sua prática um espaço de produção de conflito: o interesse de cada usuário da informação 
contábil, pois cada usuário está constituído em/por uma formação ideológica, classe social. A padronização, regras, normas etc. dos relatos contábeis instaura conflito com os interesses específicos de cada usuário da informação contábil. As exigências dos usuários internos (gestores do negócio) e as exigências dos usuários externos (financiadores, auditores e governos), fazem com que estes atores exerçam demanda/comanda de pressão na teoria contábil. A teoria contábil tem seu caráter social (de interesse público) e, concomitantemente, molda-se a um sistema de livre iniciativa de mercado, sendo que o "público" e o "mercado" podem exigir procedimentos divergentes nas questões da produção, divisão e distribuição de riquezas.

Assim, buscamos compreender a contabilidade a partir dos pressupostos de Pêcheux (Thomas Herbert), uma vez que as ciências contábeis funcionam para registrar, mensurar e controlar o patrimônio, seu objeto, que equivale ao conjunto de bens, direitos e obrigações pertencentes a uma, duas ou mais pessoas, sejam essas representadas em sua forma jurídica ou não.

Portanto, adaptando os conceitos de Herbert (2016,[1966]), compreendemos que contabilidade pode ser: "prática" pelo trabalho de processamento de dados (registrar) que resulta em informações contábeis (relatórios); "prática técnica" pelo processamento dos dados que são realizados pelo procedimento do método, da técnica das "partidas dobradas" contábeis como principal instrumento de produção de informação; "prática política" pelas utilizações das informações contábeis na (trans)formação das relações sociais de produção, pois as informações contábeis são instrumentos políticos e ideológicos; "prática ideológica" pela transformação de uma "consciência" dada em uma nova "consciência" produzida por meio de uma reflexão da consciência sobre si própria, ou seja, informações contábeis interferindo nas relações sociais dos sujeitos, como um poder que opera; "prática teórica", pois transforma um produto ideológico (princípios e normas contábeis) em conhecimento teórico; "prática social" por um conjunto complexo de práticas que são aplicadas no fator dominante da sociedade que é seu "modo de produção" (instrumentos de produção e forças produtivas como práticas políticas que organizam e formam as 
relações sociais entre os produtores); e discurso, linguagem funcionando e produzindo efeitos de sentido.

A relação concreta entre a prática técnica e a prática política, Herbert (2016 [1966]) designa a "prática empírica". Podemos pensar que a prática empírica da contabilidade se inaugurou nas relações sociais, na concepção de que existe patrimônio, algo que seja "meu" e algo que seja "seu" patrimônio, que leva ao conceito e aplicabilidade de "débito" e "crédito" e à origem das partidas dobradas contábeis, ou seja, a técnica diz o que é "meu" e "seu", e a prática política representa o funcionamento ideológico para os sujeitos do que é "meu" e "seu". Assim, pelo patrimônio, podemos considerar que este representa uma relação imaginária dos indivíduos com as suas condições reais de existência.

As condições reais de existência, no modo de produção capitalista, são aquelas que estabelecem e organizam as relações sociais dos sujeitos. Nas condições reais de existência capitalista, estamos diante da condição de um ter ou não patrimônio, de ser meu ou seu o patrimônio, ou seja, da constituição do sentido juntando-se à constituição do sujeito pela figura da interpelação que é determinada pela infraestrutura econômica dos aparelhos ideológicos e repressivos de Estado. O patrimônio "meu ou seu" se representa nos vínculos entre o "sujeito do direito", forjado pelos contratos entre sujeitos, e o "sujeito ideológico", aquele do teatro da consciência (eu penso, eu falo, eu sou, eu tenho etc.).

Consoante a Pêcheux, referente ao teatro da consciência, da interpelação, do sujeito e da ideologia,

[...] desse 'pequeno teatro teórico' da interpelação, concebido como uma crítica ilustrada do teatro da consciência, é o designar, pela discrepância da formulação 'indivíduo' / 'sujeito', o paradoxo pelo qual o sujeito é chamado à existência: na verdade, essa formulação evita cuidadosamente a pressuposição da existência do sujeito sobre o qual se efetuaria a operação e interpelação - daí não se dizer: 'O sujeito é interpelado pela ideologia'. [...] Na verdade, o que a tese 'a Ideologia 
interpela os indivíduos em sujeitos' designa é exatamente que o 'nãosujeito' é interpelado-constituído em sujeito pela ideologia. Ora, o paradoxo é precisamente, que a interpelação tem, por assim dizer, um efeito retroativo que faz com que todo indivíduo seja 'sempre-jásujeito'. (PÊCHEUX, 1995 [1975], p. 154-155, grifo autor)

Assim, o meu/seu patrimônio da fórmula contábil, como prática ideológica, em uma dada consciência que se transforma em uma "nova consciência", reflete o conhecimento sobre si e as correspondências à realidade e de concepção de mundo, ou seja, a consciência dos sujeitos. Segundo Orlandi (2012, p. 104), "a ideologia funciona pelo equívoco e se estrutura sob o modo da contradição. Não seria diferente para os efeitos que constituem a subjetividade". Em outros termos, o sujeito se banha em palavras do sistema contábil como: meu/seu e débito/crédito, que têm como efeito a determinação do lugar que lhe é atribuído pela formação social, com todo o teatro da consciência do sujeito - o sujeito sem patrimônio também tem seu lugar na formação social pela ausência/falta do meu/seu, que pode ser substituído por outros patrimônios que sejam mais do plano moral do que do capital.

\section{CONSIDERAÇÕES FINAIS}

A contabilidade tem como objeto o estudo do patrimônio, do capital. E o patrimônio/capital, em seus variados processos de significação, em especial no aspecto social e econômico, articula-se "nas relações sociais" à luta de classes. No entanto, a contabilidade, como principal ciência de estudos do patrimônio, organizada por sua técnica/ciência e também por aparelhos ideológicos e repressivos do Estado, preocupada com a mensuração, focando em processos de "modernização", "mundialização" e "globalização", concomitantemente, parece silenciar e apagar o sentido em seu discurso de luta de classes, estabelecendo desigual distribuição da riqueza, o que desencadeia tantas outras questões nas relações sociais.

O capitalismo, pelo seu jogo discursivo que materializa o funcionamento particular e ideológico capitalista, pelo delicado destaque que dá na busca por lucros, por expansão dos comércios, por competição empresarial, pelos modos de gestão etc., 
se apresenta também como exercício de poder e dominação social. Esse capitalismo produz, igualmente, sentidos a partir do discurso contábil, como linguagem dos negócios. A efetividade da discursividade contábil se constitui quando os sujeitos usam essa espécie de repertório de falas e construções simbólicas em suas ações no cotidiano social. Assim, podemos filiar a concepção de língua de vento ao discurso da contabilidade, que transforma os números, os dados, os gráficos e as informações financeiras em uma linguagem política/ideológica fluída, volátil como própria das questões do mercado financeiro. Entretanto, funciona pelo propiciar e o assegurar da rigidez dos números (dinheiro), que posiciona e submete o indivíduo em seu lugar (posição) da estrutura econômica e social.

O discurso da gestão contábil, na sua base técnico-científica, tenta produzir uma aparente exclusão da política e da ideologia como uma "coisa" oculta, neutra, somente jurídica, financista, contábil, porém, seu produto constitui-se de práticas ideológicas que funciona pelo assujeitamento de sentidos e sujeitos, uma prática discursiva que dissimula o funcionamento político dos sentidos e da ideologia.

Para o sujeito contador, a contabilidade pode ser compreendida como um lugar de sentidos homogêneos, lineares, circunscritos por uma metalinguagem e lugar de inscrição de uma profissão de extrema funcionalidade e racionalidade, de uma prática social com fins específicos e (re)conhecidos, normalmente qualificados e classificados como "precisos". O capitalismo e a contabilidade são interdependentes, e suas evoluções estão intrinsecamente ligadas aos movimentos do sistema capitalista, ou seja, a mensuração contábil simula, emula e representa o capital. Sua acumulação e não divisão.

Tomamos a contabilidade com uma prática social, a ((re)distribuição dos lucros das empresas e da riqueza, precisa de um novo discurso, equitativo entre as forças proprietárias do capital e do trabalhão. Compreendemos que (re)formar o papel da escola, da educação contábil, pelo menos para diminuir o processo de (re)produção capitalista, possibilitar uma outra concepção do vínculo imaginário dos indivíduos com as relações de produção. 
Como nas escolas já se aprende "a contar", outro verbo poderia fomentar a distribuição mais/melhor equitativa/justa dos/das bens/lucros/riquezas, o verbo "dividir", o sujeito contador seria interpelado por uma ideologia do divididor dos/das bens/lucros/riquezas de forma mais equitativa.

\section{REFERÊNCIAS}

ALTHUSSER, Louis. Ideologia e Aparelhos ideológicos de estado. Lisboa: Presença, 1970.

CANGUILHEM, Georges. O cérebro e o pensamento. Natureza Humana. São Paulo, v. $8, \quad$ n. 1 , p. 183-210. Jan.-jun. 2006. Disponível em: $<$ https://pepsic.bvsalud.org/scielo.php?script=sci_arttext\&pid=S151724302006000100006 >. Acesso em: 30 dez. 2018.

HARVEY, David. O enigma do capital: e as crises do capitalismo. Tradução de João Alexandre Peschanski. São Paulo, SP: Boitempo, 2011.

HERBERT, Thomas. Reflexões sobre a situação teórica das ciências sociais e, especialmente, da psicologia Social. (1966). In: PÊCHEUX, Michel. Analise de discurso Michel Pêcheux: textos escolhidos por: Eni Puccineli Orlandi. Campinas, SP: Pontes Editores, 2016.

Observações para uma teoria geral das ideologias. (1968). In: Rua, 1. Tradução de Carolina Rodrìguez-Alcalá. Campinas: Unicamp, p. 63-89, 1995.

HENDRIKSEN, Eldon S.; VAN BREDA, Michael F. Teoria da Contabilidade. Tradução de Antônio Zoratto Sanvicente. 1. ed. 10 reimp. São Paulo: Atlas,1999.

ORLANDI, Eni Puccinelli. Interpretação: autoria, leitura e efeitos do trabalho simbólico. Campinas: Pontes, 2004.

Discurso e texto: formulação e circulação dos sentidos. 4. ed. Campinas, SP: Pontes, 2012. 
Análise de Discurso: princípios e procedimentos. 12. ed. Campinas, SP: Pontes. 2015.

PÊCHEUX, M. Análise Automática do Discurso (AAD-69). In: GADET F.; HAK, T. (Orgs.) Por uma Análise Automática do Discurso: uma introdução à obra de Michel Pêcheux. Tradução Bras. Campinas: Unicamp, 1997.

. Semântica e discurso: uma crítica à afirmação do óbvio. Campinas: Editora da UNICAMP, 1995.

. Análise Automática do Discurso (AAD-69). In: GADET F.; HAK, T. (Orgs.) Por uma Análise Automática do Discurso: uma introdução à obra de Michel Pêcheux. Tradução de Eni P. Orlandi. Campinas: Unicamp, 1990.

PÊCHEUX, Michel; FUCHS, Catherine. A propósito da análise automática do discurso: atualização e perspectiva (1975). In: GADET F.; HAK, T. (Orgs.) Por uma Análise Automática do Discurso: uma introdução à obra de Michel Pêcheux. Tradução de Eni P. Orlandi. Campinas: Unicamp, 1997.

Enviado: Abril, 2020.

Aprovado: Maio, 2020. 